\title{
RELATO DE CASO CLÍNICO - UTILIZAÇÃO DE CIMENTO AUTO-ADESIVO (RELYX UNICEM) NA CIMENTAÇÃO DE PINO DE FIBRA DE VIDRO.
}

Danielle Medeiros VEIGA; Ederson Gonçalves BETIOL; Hércules Jorge ALMILHATTI; Archimedes Granates FARIA.

Visando simplificar a técnica de cimentação e torná-la menos suscetível aos erros do operador materiais que dispensam etapas do procedimento tem sido propostos, como os adesivos auto-condicionantes. Seguindo essa tendência, recentemente foi introduzido no mercado o chamado cimento auto adesivo de tripla presa, RelyX Unicem (3M ESPE), que elimina qualquer tratamento prévio da cavidade. Seu mecanismo de adesão se faz por meio da reação entre a matriz orgânica do cimento, composta por metacrilatos de ácidos fosfóricos multifuncionais, e a porção inorgânica da estrutura dentária, hidroxiapatita (IBARRA, 2006). Logo após sua manipulação, RelyX Unicem apresenta $\mathrm{pH}$ próximo de dois, o que promove uma remoção parcial da smear layer sem abrir os túbulos dentinários reduzindo a sensibilidade pós-operatória e a as reações pulpares (SOUZA, 2007). O caso clínico relatado tem por objetivo demonstrar a técnica de Relyx Unicem na cimentação de pino de fibra de vidro. Estudos comparativos têm demonstrado uma adequada força de adesão em dentina (HIKITA, 2007). Entretanto, relatos na literatura ainda são conflitantes no que diz respeito à formação de camada híbrida, principalmente em esmalte (WANG, 2007) e ao grau de conversão dos polímeros (TRANCHESI, 2007), requerendo pesquisas específicas para confirmar sua eficácia clínica a longo prazo. 